\title{
Pisada como Pano de Chão: experiência de violência hospitalar no Nordeste Brasileiro
}

\section{"Stepped-on like a Floor-Mat": human experience of hospital violence in the Northeast of Brazil}

\section{Annatália Meneses de Amorim Gomes}

Doutoranda em Ciências da Saúde pela Universidade Federal do Rio Grande do Norte; Assessora Técnica da Secretaria da Saúde do Estado do Ceará, Bolsista da Fundação Cearense de Apoio ao Desenvolvimento Científico e Tecnológico (Funcap).

Endereço: Rua Barbosa de Freitas, 1505, apto 80I, Meireles, CEP 60170-020, Fortaleza-CE, Brasil.

E-mail: annataliagomesळsecrel.com.br

\section{Marilyn K. Nations}

Antropóloga, Doutora em Antropologia Médica pela Universidade da Califórnia Berkeley (UCB) e San Francisco (UCSF). Professora Titular da Universidade de Fortaleza. Professora Associada da Escola de Medicina da Universidade de Harvard, Departamento de Medicina Social. Coordenadora do Projeto de Pesquisa Hospital Humano - CNPq. Líder do grupo CNPq "Cultura e Humanizacao do Cuidado".

Endereço: Harvard Medical School, Department of Social

Medicine, 641 Huntington Avenue, Boston, MA 02115.

E-mail: Marilyn_Nationsळhms.harvard.edu

\section{Madel Therezinha Luz}

Filósofa, Doutora em Ciência Política pela Universidade de São Paulo; pós-doutora pelo Cermes/Inserm, França. Professora titular da Universidade do Estado do Rio de Janeiro. Líder do Grupo CNPq Racionalidades Médicas e Práticas de Saúde.

Endereço: Praia do Flamengo 98, apto IIII, Flamengo, CEP 22210-030, Rio de Janeiro, RJ, Brasil.

E-mail: madelluzœsuperig.com.br

Financiamento: CNPq - Conselho Nacional de Desenvolvimento Científico e Tecnológico. Projeto n 403744/2004-0: Hospital Humano: etnoavaliação centrada no paciente e seus sentidos, significados e experiência vivida; e Funcap - Fundação Cearense de Apoio ao Desenvolvimento Científico e Tecnológico

\section{Resumo}

Apesar de recentes esforços para melhorar a qualidade dos serviços públicos de saúde no Brasil, iniqüidades e violência institucional persistem nos hospitais. Este estudo antropológico-crítico investiga a experiência humana da hospitalização do ponto de vista do paciente internado em um hospital público, localizado em Fortaleza, capital do Ceará, no Nordeste brasileiro. Um método qualitativo original, "O Percurso do Paciente" foi criado e utilizado, mesclando entrevista etnográfica, narrativa do paciente coletada prospectivamente durante a internação, desde a chegada no hospital até a alta, e observação-participante, seguindo-se o percurso de 13 informantes-chaves. Os resultados revelaram 225 experiências distintas de hospitalização narrados pelos pacientes. A maioria (83,6\%) dos acontecimentos foi interpretada como "desprezo" e "humilhação"; somente $16,4 \%$ foram percebidos como "zelando" pelo paciente, contribuindo para a recuperação da sua saúde. Desvelaram a progressiva desmoralização do "paciente suspeito" desde a sua recepção por um guarda uniformizado até o confisco de pertences pessoais. A hospitalização é caracterizada por abandono, solidão e aprisionamento, em virtude da imposição de normas, regras e procedimentos que ignoram a autonomia, condições pessoais e subjetividade do paciente. Apesar da estrutura opressiva, pacientes resistem às agressões, utilizando múltiplas estratégias: traços pessoais, imaginação criativa, solidariedade social e fé religiosa. Humanizar a hospitalização pública no Nordeste brasileiro requer incluir a voz e a experiência do paciente, removendo os estigmas que o prejudicam.

Palavras-chave: Antropologia cultural; Violência; Hospitalização; Poder; Humanização. 


\section{Abstract}

Despite recent efforts to improve the quality of public health services in Brazil, inequalities and institutionalized violence persist in hospitals. This critical anthropological study investigates the human experience of hospitalization from the viewpoint of patients of a public hospital located in Fortaleza, capital city of the state of Ceará, in the Northeast of Brazil. A qualitative method, "The Patient's Pathway," was created and utilized. It blends ethnographic interviews, patient's narrative collected prospectively during the entire hospitalization - from admittance to discharge - and participant observation. The pathway of 13 key-informant patients was followed. Results reveal that our patients narrated 225 distinct hospitalization experiences. The majority ( $83.6 \%$ ) was interpreted by patients as "degrading" and "humiliating" their sense of personhood; only $16.4 \%$ were seen as "caring" for the patient, contributing to the recovery of their health. A progressive demoralization of the "suspect patient" is revealed, beginning with his/her reception by uniformed guards and confiscation of personal belongings. Hospitalization is characterized as abandonment, loneliness and imprisonment, due to the imposition of norms, rules and procedures which ignore patients' autonomy, subjectivity and personal conditions. Despite the oppressive hospital structure, patients manage to resist, drawing upon multiple strategies: personal traits, creative imagination, social solidarity and religious faith. Humanizing public hospitalization in the Northeast of Brazil requires including the patient's voice and experience while removing harmful stigmas.

Keywords: Cultural Anthropology; Violence; Hospitalization; Power; Humanization.

\section{Introdução}

As reformas do Estado e as políticas de saúde nem sempre favorecem a dignidade humana na prática dos serviços (Nations e Nuto, 2002; Deslandes, 2004). Perduram as lacunas no acesso, a baixa qualidade, a precariedade nos serviços, a hegemonia do modelo biomédico calcado na lógica tecnicista, menosprezando a complexidade dos fatores que afetam a saúde das pessoas (Capra, 1996; Luz, 2005). Persiste, ainda, o desrespeito aos direitos dos usuários, embora legalmente preconizados (Brasil, 20o6b).

São emergentes, entretanto, a visão e a prática de integralidade, efetivando direitos constitucionais, e a humanização na saúde ganha importância no debate da saúde pública no Brasil (Benevides e Passos, 2005; Deslandes, 2005). Nos últimos três anos, o Ministério da Saúde desenvolveu a Política Nacional de Humanização na Atenção e Gestão em Saúde (PNH: Humanizasus), de ação pública e transversal (Brasil, 2006b). Fundamentada na reforma sanitária, base constituinte do Sistema Único de Saúde (SUS), a proposta pretende fortalecer os princípios da integralidade, resolubilidade e eqüidade num "SUS que dá certo". Resiste ao modelo excludente e de mercantilização da saúde (Martins, 2003). Contribui, assim, para "uma atenção integral, equânime com responsabilização e vínculo, pela valorização dos trabalhadores e avanço da democratização da gestão e do controle social participativo" (Brasilb, 2006, p. 9).

Apesar desses esforços para melhorar a qualidade da saúde pública, iniqüidades são desveladas nos hospitais (Giglio-Jacquemot, 2005; Nations e Gomes, 2007), desafiando transformações sociais. Modificar esse quadro é difícil, pois há resistências à efetivação dos direitos humanos no Brasil, uma sociedade violenta, autoritária, vertical, hierárquica e oligárquica, polarizada entre a carência total e o privilégio absoluto (Chauí, 2006).

A palavra "violência" vem do latim violentia, designando "ato de violentar; constrangimento físico ou moral; uso da força, coação" (Ferreira, 1975, p. 1463). No senso comum, entende-se pelo uso de palavras ou ações que constrangem e machucam as pessoas; o uso abusivo do poder, que resulta em ferimentos, sofrimento, tortura ou morte. Existem outras formas de violência, entretanto, além da força física, que são até mais 
agressivas, opressoras, dominadoras e complicadas de encarar, pela sutileza com que se escondem no nível macro estrutural, no contexto institucional, nas relações sociais e nos significados simbólicos (Luz, 1979).

A "violência estrutural" (Abadia-Barrero e Castro, 2006) é uma força macrossocial no âmbito políticoeconômico, que limita injustamente o acesso às oportunidades dos desfavorecidos. Quando o poder abusivo do Estado se concretiza nos espaços institucionais, temos a "violência institucionalizada" (Goffman, 1963), caracterizada pelo encarceramento e a tutela que controla a vida de alguns segmentos da população. Nas instituições, a forma mais insidiosa de violência, exercida pelos seus agentes sobre as classes populares, de acordo com o sociólogo francês Pierre Bourdieu (1991), é a "violência simbólica”. Ocorre quando o poder impõe sua visão do mundo social e distinções entre pessoas como legítima, disfarçando os reais interesses e as relações de poder desiguais vigentes, a ponto de se tornar aceitável por ambos, dominadores e dominados. Na saúde, o hospital tornou-se um instrumento terapêutico sistematizado com a introdução de normas e mecanismos disciplinares desde o século XVIII (Foucault, 1993). Objetivamos, com esse estudo, revelar as experiências vividas na hospitalização, os significados simbólicos e as estratégias de resistência pela óptica do paciente internado no hospital público no Nordeste brasileiro.

\section{Metodologia}

De janeiro a julho de 2005, esta pesquisa antropológica foi realizada em um hospital geral público, localizado em Fortaleza (população: 2.200.ooo habitantes), capital do Ceará, no Nordeste brasileiro. Trata-se de um contexto apropriado para investigar o impacto das iniqüidades sociais no cuidado institucionalizado. A Região Metropolitana de Fortaleza é marcada pela disparidade socioeconômica e a segregação crescente: a distância média entre os 10\% mais ricos e os $40 \%$ mais pobres, cresceu de 13,3 para 18,7 vezes entre 1991 e 2000 (Bernal, 2006).

Situando o paciente no seu universo de significação (Geertz, 1989), utilizamos uma combinação eclética de técnicas, que criamos e a denominamos "O Percurso do Paciente (The Patient's Pathway)". Durante o primeiro mês foi realizada observação livre dos arre- dores e do ambiente interno do hospital, registrada em diário de campo. Acompanhamos três cirurgias, três casos de morte e oito mulheres em trabalho de parto. Durante os dois meses seguintes, foi feita observação participante, em todos os horários e dias da semana, dos diversos "momentos vividos" por aproximadamente 50-6o pacientes na hospitalização, como: chegada, transporte do paciente, barreiras ao atendimento, visita de familiares, exames, cuidados e procedimentos, alimentação, rituais religiosos, parto, comemorações, cirurgias, má notícia, morte, alta hospitalar entre outros.

Durante os quatro últimos meses aprofundamos o estudo etnográfico, seguindo de perto o percurso de 13 pacientes, desde sua chegada no hospital até a alta, variando entre sete horas e 60 dias, dependendo de sua permanência no hospital. A seleção desses 13 informantes-chaves foi aleatória pela: 1) identificação na chegada; 2) escolha do primeiro na fila do atendimento; 3) inclusão de pelo menos um de cada serviço); 4) tomada de casos diversificados. Dos 13 pacientes selecionados, quatro são homens e sete mulheres entre 16 e 93 anos. A maioria (61,5\%) é casada; $23,1 \%$ são solteiros e $15,4 \%$, separados. A maioria $(84,6 \%)$ reside na periferia de Fortaleza e 15,4\% em outros municípios do Estado. Quase a metade ( $46,2 \%)$ é analfabeta ou não completaram o primeiro grau; $7,7 \%$ terminaram o primeiro grau e $46,1 \%$ estão cursando ou concluíram o segundo grau. A maior parte $(53,8 \%)$ é inativa economicamente, sendo desempregados, donas de casa ou aposentados; 46,2\% trabalham com baixa remuneração ou por conta própria. Mais de dois terços (77\%) internaram-se pela primeira vez e $23 \%$ por duas ou cinco vezes. Foram excluídos pacientes com transtorno psíquico de natureza grave, aqueles impossibilitados de expressão verbal e menores de 16 anos. Os casos incluíram: uma pré-eclâmpsia, um parto normal, prematuro e de alto risco; biopsias pulmonar e uterina; cirurgia estética vaginal, bariátrica, histerectomia, tireóide e retirada de nódulo no pé; um problema reumatológico e um caso de leishmaniose cutânea.

Para mergulhar no mundo hospitalar na óptica do paciente e captar sua interpretação da experiência durante todo seu percurso dentro da instituição, mesclamos a entrevista etnográfica (Spradley, 1979) com a narrativa do paciente (Kleinman, 1988) sobre os acontecimentos vivenciados e a observação participante. 
O desafio é enxergar o contexto de experiência moral do próprio paciente, que "é sempre modificado e normalmente incerto” (Kleinman, 2006, p. 25) no seu mundo local, o ambiente hospitalar.

As entrevistas etnográficas profundas e abertas prolongaram-se durante toda a internação, de forma flexível, foram guiadas, mas não limitadas, por questões norteadoras que favoreciam a descrição de situações, a revelação de contrates vividos, significados, e eram modificadas no contexto da conversa: 1 ) Conteme como está sendo a sua permanência no hospital; 2) Descreva como foi para você ficar internado; 3) Descreva para mim algum evento que o fez se sentir melhor/pior no hospital; 4) Relembrando desde sua entrada no hospital e tudo o que viveu, conte-me o que podia ser feito para tornar a sua convivência mais humana; 5) Tem algo mais a dizer sobre a sua passagem pelo hospital? Em momentos oportunos, os pacientes foram incentivados a narrar livremente sua versão dos acontecimentos no instante em que ocorriam. Assim, as narrativas de 13 pacientes reais (apenas os nomes são fictícios), estimularam a formulação e a expressão espontânea de críticas das suas circunstâncias. Essa coleta prospectiva, na presença das pesquisadoras, principiava com uma frase ou pergunta desencadeadora: "conte-me o que está acontecendo", “como você está se sentindo agora?" colocando-o em contato com seus sentidos. Com o aumento da confiança nas pesquisadoras, as narrativas aconteciam espontaneamente. As entrevistas e narrativas foram gravadas e, posteriormente, transcritas na íntegra, produzindo um volumoso texto de 331 páginas em espaço simples.

Após leituras flutuantes e repetidas dos depoimentos, emergiram 225 narrações distintas, ou unidades de significação, sobre a experiência da hospitalização, que foram agrupadas em 23 temáticas, utilizadas para codificar as transcrições de acordo com a Técnica da Análise Categorial (Bardin, 2002). Aprofundamos nesse artigo seis temáticas: o cenário da pobreza, o paciente suspeito, a prisão hospitalar, o poder, o estigma e as estratégias de enfrentamento do paciente. Reconstruímos a experiência de adoecimento e o percurso de hospitalização - chegada, admissão, internação e alta - de cada um dos 13 pacientes, com ênfase no seu pensar e agir. Inspiramo-nos na "interpretação semântica contextualizada” dos antropólo- gos Bibeau e Corin, que interligam a experiência individual de pessoas, aqui os pacientes, aos sistemas de significação e avaliações que ele ou ela atribuem; e as reações tomadas, ou não, por eles, diante dos condicionantes estruturais da instituição (Bibeau, 1988; Bibeau e Corin, 1995). Finalmente, refletimos sobre essas interpretações à luz dos referenciais teóricos da Antropologia Médica (Abadia-Barrero e Castro, 2006; Castro e Farmer, 2005; Farmer e col., 1996; Kleinman, 1988, 2006; Nations e Monte, 1996; Nations e Nuto, 2002; Uchôa e Vidal, 1994), que situam o ponto de vista do paciente e seu modelo explicativo; a Sociologia da Saúde (Swartz, 1997; Luz, 1979, 2004) na perspectiva da compreensão dos fenômenos sociais de exclusão, e a humanização do cuidado (Benevides e Passos, 2005; Deslandes, 2005; Brasil, 2006b; Buss, 2003) que visam ao paciente como protagonista e cidadão de direito.

Optamos por apresentar as falas com uma escrita que entrelaça a voz do paciente e a das pesquisadoras, tendo o cuidado de destacar as expressões que lhes pertencem. Os cuidados éticos foram seguidos de acordo com a Resolução 196/96 do CNS- MS-Brasil, que regulamenta pesquisas com seres humanos (Brasil, 2001).

\section{Resultados}

Na visão do paciente nordestino internado no hospital público na capital de Fortaleza, Ceará, a experiência é marcada pelo sofrimento, desprezo e estigmatização. Das 225 experiências distintas sobre a vivência hospitalar narradas por nossos informantes, identificamos uma multiplicidade de sentidos. A maioria 188 (83,6\%) dos acontecimentos significaram "desprezo" e "humilhação”. Em menor freqüência, 37 (16,4\%) das vivências na instituição foram considerados "zelosas", ou seja, os pacientes sentiram-se tratados "como se fosse gente,” contribuindo para a recuperação da sua saúde.

\section{O cenário da pobreza e o paciente suspeito}

Antes da chegada ao hospital, o paciente atravessa a praça histórica da Lagoinha, a "Feira do Malandro" e o "Beco da Poeira”. Ali, cordões de ouro, relógios, aparelhos eletrônicos e armas roubadas nos assaltos dos bairros nobres de Fortaleza são vendidos clandestinamente a "preço de banana" para se "desfazer" rapida- 
mente deles, antes que a polícia descubra o crime. No labirinto das barracas, são vendidos CDs piratas e produtos contrabandeados da China e do Paraguai, sem nota fiscal.

O paciente de baixa renda, com sua família, já entram no hospital suspeitos de serem malandros da feira, "marginais", "bandidos" ou "ladrões" de quadrilhas que assaltam a cidade. Aquele que será institucionalizado é filmado pela câmera de segurança; suas sacolas são vistoriadas e seus objetos confiscados por dois guardas fardados; não é permitida a entrada de bens particulares. Observamos um acompanhante abrir sua mala, retirar as coisas do paciente e colocar num saco plástico transparente, sob o olhar vigilante do guarda. Uma recepcionista responde às solicitações, mas não saúda com boas-vindas. Uma pintura de enfermeira pede silêncio, enquanto o barulho dos ônibus que circulam na rua invade o ambiente pelas grades de ferro. Na emergência obstétrica, um quadro dos Direitos do Paciente na parede informa: $O$ atendimento digno no serviço público é um direito de quem cumpriu seu dever de contribuinte. EXIJA-O!

\section{"Prisão" hospitalar: uma experiência de confinamento}

O hospital é percebido pelo paciente como uma prisão, um confinamento, como se estivesse "dentro de uma caixa”. Causa claustrofobia, "agonia”, "depressão" e até a "perda do juízo". É lugar de estranhamento, abandono e solidão que "aumenta com os dias, piorando na noite e nos domingos”. Há pouca liberdade e a identidade do paciente é despojada pela norma: vestimenta listrada com números grandes destacados, guardas nas portas de entrada, grades nas janelas, placas proibitivas, ambientes fechados e limitação dos contatos com familiares. Pacientes "presos" no segundo andar "pegam ventinho" na janela de grades de ferro, enquanto olham o movimento da rua: uma pessoa querida passando, sentem o cheiro da tapioca assando e vêem a luz do sol. É a janela da vida, "o cantinho mágico... O canto da saudade!” Paradoxalmente, "a gente vem buscar a vida no hospital".

O discurso dos participantes retrata a "prisão hospitalar”. Matias, 42 anos, desempregado, reclama do enclausuramento: "Você passa o tempo todo se sentindo mal por não estar com a sua família... não tem um local pra pessoa arejar, passear, ver movimento, né? Só é ruim esse isolamento que a gente fica”. Dona Guiomar, 83 anos, internada há 30 dias, não percebe "nada de bom em estar em hospital". Aguardando sua cirurgia, exclama: "Entrar no hospital é fácil, para sair é mais difícil!” Após 48 horas do parto, uma mãe interroga: "por que nos prendem aqui? Meu bebê está normal. Quero ir para casa. Bom mesmo é a casa da gente". Durante tratamentos externos, a bata listrada confunde pacientes do hospital com presidiários que usam o mesmo padrão de vestimenta.

A alta hospitalar, portanto, é a sonhada libertação, a volta para o seu mundo: à casa, à família, aos amigos, ao trabalho e ao lazer. 0 lar é espaço de conforto onde "sou mais bem cuidado", com “dedicação e atenção total", onde "a comida eu mesmo faço, um feijãozinho mais calibrado... Comer fazendo enroladinho com a mão!" (Mano, 93 anos, analfabeto). Para o Sr. José, agricultor com câncer, permanecer "encangado" aos fios da alimentação parenteral, a internação é semelhante a "um cabresto" insuportável. Queria ir embora, pois sonha "depois de operado comendo peixe (...) nada melhor do que a casa da gente!”. Sentindo saudades da vida lá fora, outra paciente lamenta: "Meu Deus, se eu tivesse em casa agora eu estaria com meu bebê, comendo pão e tomando café”. Um aposentado, o sr. Mano, 93 anos, anseia sua libertação: "Graças a Deus, vou sair dessa prisão... sente preso, né? Sem ver ninguém, só a porta e, ainda bem que tinha uma televisãozinha pra gente saber alguma coisa do mundo de fora".

\section{0 poder hegemônico instituído}

$\mathrm{Na}$ entrada do hospital, o paciente confronta-se com uma galeria de placas homenageando o poder instituído de políticos e ex-diretores. Um cartaz na parede do ambulatório adverte: "Desacatar funcionário público no exercício de sua função ou em razão dela pena de detenção de seis meses a dois anos ou multa (Artigo 331)".

Na emergência, uma corrente de aço e um policial barram a entrada de pessoas "não autorizadas". Um motorista de ambulância ressalta a "autoridade medonha" no hospital: "A gente quase sempre é humilhado. Já é difícil fazer as coisas, e eles tornam as coisas ainda mais difícil”. A atitude do profissional é percebida como arrogante, pois "rebaixa” o paciente: "quando veste aquela roupa branca, se sente todo-poderoso".

A Central de marcação de atendimentos concentra 
poder institucional. Uma parede de vidro separa o paciente dos atendentes no comando; comunicação somente por meio de um microfone. Não há a quem responsabilizar. A "central” impessoal decide a vida das pessoas, indicando onde a mulher terá seu bebê, se ficará internada ou se seguirá para outro hospital: "o pessoal da Central é quem faz esse trabalho... Só as meninas sabe”.

As normas são inquestionáveis, autoritárias e coercitivas: não é permitida visita fora dos horários previstos, é proibido entrar com alimentos, e não se pode ter acesso vestindo bermudas ou minissaia, por exemplo. A rotina estabelece obediência ao poder, sem respeito à singularidade do paciente e da família. O guarda proibiu um marido de entrar fora do horário da visita, apesar da gravidade da saúde de sua esposa; uma linha simbólica que não podia ser transposta demarcava o limite que separava os dois, obrigando-os a conversar afastados. É regra tomar banho, independentemente do desejo, horário ou condição física. 0 acompanhante deve receber sua espreguiçadeira à tarde e entregá-la às oito da manhã do dia seguinte, ainda que precise dela para descansar. É proibido acompanhante no parto, mesmo previsto em lei. Não é autorizado utilizar roupas próprias. É norma a gestante vestir-se da "roupinha da Barbie", uma bata rosa, listrada, padronizada, com o nome e número da unidade estampados em letras graúdas, ou com o fardamento amarelo, que as gestante comparam ao gari que limpa as ruas da cidade.

A deterioração física do ambiente hospitalar é percebida como um ato de desprezo pessoal. É o leito quebrado, o colchão desgastado, o banheiro sujo, os equipamentos avariados que causam sofrimento, sentimentos de abandono e rejeição no paciente e em sua família: "até minha cama tá agressiva, é quebrada, o colchão afundado... o banheiro não tem luz... Pra gente entrar no banheiro à noite, tem barata, essas coisas, sabe?” Essas más condições são vistas como um grande "azar" pessoal. Matias, 42 anos, obeso, aguardava uma cirurgia de redução do estômago há três anos, sem sorte: "Levei um pouquinho de zebra, o aparelho tava quebrado... Oh! Coisa para sofrer é pobre!”. A precariedade, às vezes, leva o paciente a suplicar: "Senhor, misericórdia por essa cama tão dura!".

Com a desorganização da rede de serviços, o paciente sente-se como uma "barata tonta, sem rumo ne- nhum", desorientado e perdido, diante da dificuldade de marcar exames, consultas ou cirurgias. A sensação de "não saber" em toda a internação produz insegurança, tensões, ansiedades e impotência, fragilizando a pessoa. Miriam, 21 anos, gestante de alto risco, se queixa: "Fiquei baratinada, feito barata tonta, porque foi um choque eu ter ficado aqui dentro, sem ter avisado ninguém, sem saber de nada... Senti-me sozinha e abandonada". Com dores de parto, foi esquecida numa maca dentro do banheiro: "Eu sei que os leitos estavam todos lotados, entendeu? Tinham que me levar para dentro de um banheiro, eu me senti tão rejeitada... porque sei lá... não me deram lençol”. Em seguida foi levada para "uma sala de parto desativada e sem luz... Eu fiquei encolhidinha”.

\section{Estigma institucional e desmoralização do paciente}

O sentimento de menos-valia é comum entre os pacientes que se sentem "um nada, bem pequenininho". Discriminado como pobre, as metáforas que se referem à pobreza, à marginalidade e a um status social indesejável são associadas à sua identidade, reduzindo-o, assim, à condição de vítima. É estigmatizado como "um coitado", "uma criança”, um "malandro", “um marginal”, "um criminoso", "um gari”, "um limpador de banheiro", "uma figura folclórica africana de travessuras", ou ainda "um objeto", "um brinquedo", um "pano de chão, que todo mundo pisa”.

Amélia, uma mulher madura, é "discriminada” com gestos e palavras da auxiliar de enfermagem. É tratada como "uma coitada, uma criatura inútil, uma criancinha - as piores palavras para uma pessoa, pois significa que não pode fazer nada por si mesma!”. Apesar do nome escrito na placa de fórmica ao lado do leito, uma paciente disposta a trocar o lençol da cama é interrompida pela auxiliar: "Bebê, deixe que eu faço!". Chorando, uma filha desabafa sobre "violência" sofrida pela mãe: "Dizem que minha mãe é largada... que ninguém olha para ela! Já fui muito pisada... maltratada. Eu tava fazendo o que podia. Não estudei para saber de tudo (...) o que me dói é ver a agressão de um ente querido sofrendo!" Observamos a nutricionista comparar uma paciente com o pé enfaixado ao Saci, quando pulou até seu leito numa só perna: "Isso, Saci Pererê, vai, vai pulando!”. Depois, emite juízo de valor 
sobre a ausência da sua mãe: "Ela é igual beija-flor... eu não gosto de mãe assim, não!”. Estevão, semi-analfabeto, recuperando-se da quinta cirurgia, iguala-se a uma marionete, sem vontade própria: "Elas botam pra lá, pra cá, faz da gente brinquedo". Sentiu-se descartado quando, recebeu alta na véspera do Natal: "Iam fazer uma limpeza na área e fui na leva dos outros, mesmo sem estar bem". Uma gestante de alto risco refere-se à sua classe social "inferior", como se fosse um pano de chão: “(...) sai da casa da gente tudo bem direitinho... chega num local desse e é tratada como se fosse um pano de chão, pisado por todo mundo. Eles que sabem tudo ou acham que sabem. Só porque são melhor de vida... porque não é de igual pra igual, né?”. Familiares também são desqualificados como sujeitos do cuidado. Os acompanhantes recebem uma lista de tarefas "domésticas" para cumprir no hospital: "Só falta dizer que tem que lavar o banheiro!”.

\section{Enfrentamento da "autoridade medonha"}

O paciente e a família enfrentam o poder institucional e se indignam com a agressão "absurda”. Denunciam abertamente: gritam nos corredores por notícias da mãe morta, xingam as atendentes da Central, registram queixa na Ouvidoria e ameaçam chamar um programa popular de televisão, "Barra Pesada”. Revoltamse contra o desperdício do dinheiro público, criticam a corrupção política e o desvio de verbas. O paciente se sente roubado e injustiçado pela falta de ética, como relata Cláudio, 67 anos, aposentado: "O desperdício maior é o rabo-de-couro, o ladrão, o guabiru; o rato não vem em sua casa e mexe em tudo? A mesma coisa o político, o administrador do hospital, ninguém pega devido à impunidade (...) a metade do dinheiro da compra do soro vai para o bolso dele!".

Atos de protesto sutis, escondidos nas entrelinhas dos discursos, resguardam o anominato do paciente, que corre menos risco de ser punido: "Se a gente quer ter saúde, tem que agüentar o que vier. Se reclamar é pior!". Identificamos quatro modos de resistência à subordinação: a) traços da personalidade; b) formas de pensar e agir auto-protetoras; c) apoio de amigos e familiares; d) fé e transcendência espiritual.

Cada paciente utiliza suas características pessoais para superar a agressão vivida. Uns "suportam tudo" com paciência, conformam-se com as longas filas, desinformação e momentos desagradáveis: "Tô bebendo, comendo, dormindo, dá pra agüentar". Outros batalham contra as injustiças "por si mesma”. Elvira, 50 anos, enfrentou a espera de três anos para marcar sua histerectomia, "batendo de porta em porta", até achar uma médica que driblou as barreiras. Fugir do contexto no pensamento, desligando-se do momento vivido pelo sono, fantasia ou "fazendo de conta", é outra estratégia de enfrentamento. Um paciente protesta em entrelinhas contra o descuido da enfermeira: "Não posso nem dizer, mas percebo que ela não tá fazendo de bom gosto... a gente não gosta, mas tem que aceitar gostando!". Outro, compara-se com pessoas em pior situação para aceitar a própria condição. Matias, 42 anos, na clínica cirúrgica, usa a ironia para criticar: "Vou convidar o Sr. Lúcio [O Governador do Ceará] para vim ver o apartamento. É muito "bonita" essa caminha bem estreitinha... Imagine, um cara como eu com quase duzentos quilos, deitado nessa cama pequena!...É última geração!”. Alguns fazem questão de não seguir as regras impostas: "tem os avisos dos horários de ligar a televisão, mas ninguém cumpre”. Outros deixam suas queixas anônimas nas caixas de sugestão.

Contrapõem-se, também, ao poder dominante, criando laços de solidariedade com outros pacientes, familiares, amigos e acompanhantes. A troca afetiva "dá força à gente", pois contraria a assistência "impessoal e fria”. Miriam, 21 anos, mãe solteira, sentindo-se abandonada, conta com a ajuda das companheiras de quarto: "A gente estava ali com o mesmo problema... quando uma tava triste a gente sempre animava!". Uma rede de apoio social é criada com rodas de conversa, favorecendo compartilhar histórias de vida, dificuldades, informações sobre a doença e medidas alternativas de tratamentos. Visitas diárias e telefonemas da família e amigos tornam a internação suportável.

Finalmente, a crença em Deus, a prática da oração e leitura da Bíblia ajudam a ultrapassar momentos de incerteza, dor e solidão, como revela Eva, dona-de-casa, 56 anos: "Se eu não tiver fé em Deus, em quem eu tenho? Ele me levanta, ajuda a melhorar mais, alimenta o espírito... A gente não se sente tão só aqui... Ele não abandona ninguém”. No corredor do berçário de alto risco, mães desesperadas colocam na imagem de Nossa Senhora as pulseiras de identificação dos seus bebês com pedidos de cura. 


\section{Discussão}

A expectativa da internação hospitalar do paciente nordestino, na maioria empobrecido, doente e vulnerável, é de ser "abençoado" com a melhoria na sua saúde. No percurso pela cura, deixa para trás sua casa, família e modo cultural de viver, para se confinar distante de tudo e de todos, "buscando a vida no hospital". Espera encontrar ajuda profissional, um cuidado "zeloso", acolhimento. A experiência de hospitalização, entretanto, na grande metrópole Fortaleza, é marcada, paradoxalmente, por agressão, humilhação e desrespeito à sua pessoa e a seus direitos. Longe de promover a saúde, a internação freqüentemente resulta em sofrimento, em razão de abuso de poder, discriminação e desmoralização. 0 paciente "está ali porque é o jeito", precisa do cuidado, mas, no final das contas, é um direito de cidadania. Na complexidade humana (Morin, 200o) e suas contradições, a alta hospitalar significa um alívio da violência institucional. A volta do paciente para casa é percebida como o final do "aprisionamento", a recuperação da sua liberdade e o reencontro com pessoas que desejam o seu bem.

A desilusão com o hospital como lugar de cura milagrosa é substituída pela idéia de prisão e, conseqüentemente, a internação torna-se um aprisionamento forçado, contra a vontade. No imaginário popular, a estrutura física, o vestuário, a comunicação etc. conspiram para a constituição da imagem do "hospitalprisional": grades de ferro nas janelas, a entrada barrada, a vistoria e confiscação de pertences, a central de comando, batas listradas e os avisos de regras e proibições. Na verdade, quem é preso atrás das grades nessa metáfora não é a pessoa doente e fragilizada precisando de cuidados, nem um paciente sem nome, mas, o "malandro da Feira da Praça" que invadiu o hospital. Transfigurado em criminoso, o paciente suspeito merece ser confinado e punido. Assim, justificam-se a indiferença, o descaso e os maus-tratos que sofrem durante a hospitalização.

Nossa interpretação não deve surpreender, uma vez que Foucault $(1980,1993)$ já descreveu o hospital, desde sua origem, como um lugar de empobrecidos e disciplinador, estabelecido pela ordem médica, evoluindo para a despersonalização do paciente internado (Helman, 2003). Goffman $(1963,1974)$ também, considerou tanto o hospital mental quanto o presídio insti- tuições totais, pois neles as pessoas são segregadas da sociedade por um período de tempo variável, permanecendo fechadas, isoladas e formalmente administradas. Ao adentrar o estabelecimento prisional, o apenado é submetido a seis tipos de mutilações: 1) separação do mundo externo; 2) privação da sua identidade; 3) espoliação do seu papel social; 4) ameaça à segurança pessoal; 5) aviltamento à sua pessoa; e 6) violação da privacidade. Juntas, essas agressões humilham, degradam, e mortificam o eu do detento (Goffman, 1974) .

Todas essas formas que desagregam o ser social do paciente foram encontradas nas narrativas: seguranças recolhem os bens pessoais; a carteira de identidade é confiscada; os familiares são afastados por uma linha divisória imaginária; a vestimenta é uniformizada pela camisola ou pijama; os horários são controlados e o corpo é exposto com a bata aberta atrás. Faz sentido que o paciente perceba essa vivência como um aprisionamento, pois a sua subjetividade é desconsiderada, suas necessidades humanas controladas, as saídas proibidas e seus vínculos sociais rompidos. Assim, ele perde sua autonomia e liberdade de ir e vir, seu modo de viver, de se expressar e até de controlar o próprio corpo, o espaço e o uso do tempo. É obrigado submeter-se aos cuidados de profissionais estranhos, independentemente da vontade.

Luz (1979) acentuou que o poder institucional divide os indivíduos entre comandantes e subordinados obedientes. As relações sociais assumem a forma de tutela, de dependência e favor; robustecendo o poder e saber vigentes pela obediência à hierarquia dominante. Em instituições como os hospitais, portanto, o paciente não é visto como sujeito autônomo e cidadão portador de direitos (Brasil, 2006a). Apesar disto, ele denuncia a violência institucional pública, por meio da metáfora popular do hospital-prisional, um retrato-falado da opressão humana. Basta escutar para constatar.

No hospital estudado desvendamos ainda o fato de que o poder hegemônico é instituído e cristalizado pelo menos por quatro formas distintas de imposição sobre o paciente: 1) uma ideologia institucional autoritária; 2) normas, regras, rotinas e protocolos que regulamentam e moldam o comportamento;3) condições físicas decadentes; e 4) estigmas que discriminam. São tipos de violência particularmente nocivos, pois 
abrigam na ordem legal e institucional do hospital, reproduzindo a desigualdade como algo natural (Luz, 1979). O hospital e seus agentes profissionais usam suas práticas autoritárias de gerenciamento como um fim em si mesmo, banalizando a violência, pelo abuso injusto do poder. O paciente é submetido a essa autoridade medonha, tornando-se uma figura instituída da desigualdade (Luz, 1979, p. 38). Não importa se a autoridade é exercida pela linha descendente da administração, com rígida hierarquia e centralização ou pelo poder-saber médico (Lima e col., 20o6), sua imposição absoluta é necessária para manter a ordem institucional. Afinal, é mais fácil dominar quando se restringem a liberdade de pensamento e a expressão do paciente.

Embora a imposição de normas, regras, rotinas e protocolos padronizados possam, teoricamente, facilitar o fluxo dos pacientes, conferir agilidade aos processos de trabalho e melhorar o conforto e a qualidade dos serviços, observamos, durante o trabalho de campo, que sua função reguladora se torna freqüentemente instrumento de dominação (Luz, 1993). É o elo entre as relações institucionalizadas de poder e os regulamentos que asseguram a continuidade da dominação institucionalizada (Luz, 1979, p. 33). Ao predominar a racionalidade burocrática e tecnocientífica, há rigidez, emperramentos, longa espera e caos, em vez de eficiência, (Luz, 2004).

Do nosso ponto de vista não é por acaso que o paciente hospitalar vive num constante estado de "não saber de nada", como se fosse "uma barata tonta”, perambulando pelos corredores do hospital; para o poder imperar; é necessário enfraquecer, colocar o paciente numa situação de ambigüidade, no limbo, induzir uma sensação de vulnerabilidade e liminalidade (Turner, 1969). "Desorientado", sem status de sujeito na sociedade, torna-se mais manipulável e controlável.

O poder hegemônico no hospital público se instala, também, quando submete o paciente a condições físicas subumanas. Constatamos condições de atendimento e estrutura física precária, apesar de reformas e melhorias ambientais constantes. 0 que impressiona é como até as estruturas e objetos inanimados uma parede de vidro, um balcão alto, um colchão de cama "afundado" - são capazes de agredir e desvalorizar um ser humano. Para o paciente um banheiro sem luz e sujo, um equipamento quebrado, uma cama “agressiva" é fruto de seu status social "de pobre". A falta de verba do Estado para investir na infra-estrutura hospitalar representa vai além de cofres públicos vazios, pois significa para o paciente de baixa renda que ele não merece o melhor, que é uma segunda classe de pessoa, incapaz de pagar por um serviço igual ao das elites de Fortaleza.

Descobrimos que o poder hospitalar é instituído por estigmas distintivos das pessoas - autoridades e pacientes - reforçando a submissão e exclusão daqueles julgados como socialmente inferiores ou indesejáveis. As metáforas que o paciente utiliza para expressar essa discriminação são estabelecidas a partir da linguagem, do sistema de códigos e referenciais culturais (Bourdieu, 1991). Constatamos que o paciente carrega consigo o estigma de ladrão, bandido, marginal e malandro, que o hospital reforça, levantando suspeitas sobre seu caráter moral e sobre sua honestidade. As metáforas do "pano de chão", "gari”, "lavadeira de banheiro" associam sua imagem a algo sujo, nojento, repugnante. Desperta no seu imaginário conotações de alguém "imundo", "fedorento", que transmite doenças. Simbolicamente, o paciente se transforma em algo ofensivo e perigoso, que merece "ser pisado por tudo mundo". Essas metáforas criticam sua condição de classe desfavorecida.

O estigma da "boneca-Barbie", um brinquedo que ninguém leva a sério e manipula, degrada a mulher cearense, já alvo de reconhecida violência doméstica e assassinatos por parceiros íntimos (Brasil, 2006c). A dominação masculina não só oprime mulheres na sociedade nordestina, mas replica-se nas relações de gênero dentro do hospital. Condutas profissionais que desprezam a mulher são observadas a todo instante: uma gestante abandonada em trabalho de parto no banheiro junto a baratas, uma mulher que deu à luz deixada numa sala escura, uma jovem pós-parto esquecida, sangrando, sem absorventes ou calcinhas etc. Jamais a mulher cidadã é uma "boneca-Barbie", "bebê" ou "Saci-Pererê". Enxergá-la assim é violentá-la em sua dignidade e reforçar a submissão. Confirmamos, portanto, que o estigma funciona para que o poder diferencie as classes, gêneros, raças, etnias, idades etc. dos pacientes, para melhor discriminá-los e dominálos (Farmer,1999; Castro e Farmer, 2005). Assim, a "autoridade medonha" reforça a desigualdade social nesse hospital em Fortaleza, cidade já marcada pela 
disparidade de classes econômicas e segregação social (Bernal, 2006).

Finalmente, corroboramos o pensamento do cientista político James Scott (Scott, 1990), segundo o qual, diante da repressão intolerável, a pessoa oprimida jamais se submete totalmente, sem protestar, à injustiça que a insulta. Na medida em que a opressão aumenta, "os enfraquecidos" (pacientes empobrecidos) criam "roteiros escondidos", cada vez mais sutis, para resistir à dominação. Sem poder arriscar o confronto direto com o poder, desfazem sua indignação nas entrelinhas das narrativas, metáforas e afirmações irônicas etc., que escapam à punição. São táticas de protesto prudentes.

Para resistir a ordem gerencial e ao saber-poder dos profissionais e tornar o ambiente hospitalar tolerável, o paciente, como outras populações oprimidas no Ceará (Nations e Monte, 1996), conjetura um micropoder (Foucault, 1980); uma resistência legítima diante do poder reinante. De acordo com Scott (1990), quanto mais intensa a opressão, mais nocivos e sutis se tornam os atos de protesto. Os pacientes criam "roteiros escondidos", chamados de "armas dos enfraquecidos" para enfrentar o poder institucional, uma crítica que jamais poderia ser expressa abertamente.

O paciente estabelece, ainda, redes sociais de apoio que trazem notícias de casa, palavras de conforto e afeto, que o fortalecem contra o isolamento, a solidão e o confinamento no hospital. Entendemos que o forte sentimento de fé em Deus e rituais religiosos praticados nas enfermarias seja uma resistência difusa à medicalização autoritária de seus corpos (Foucault, 1980).

Diante da violência institucional, desvendada tão detalhadamente na viva voz de nossos informantes, seria ingênuo da nossa parte pensar que programas e ações contingentes ou isoladas de humanização sejam capazes de transformar a realidade de dominação. Luz (1979, p. 16) enfatiza, que "nenhuma dessas resistências deslocam ou sequer arranham a dominância do discurso hegemônico; ao contrário, tendem a se subordinar à sua dominação", Ao mesmo tempo, admite que "as instituições são o lugar privilegiado da luta política” (Luz, 1979, p. 31).

Reconhecemos, entretanto, que se trata de uma luta desigual, travada com armas diferenciadas de poder. Parece-nos que a humanização desse campo de batalha, desse "presídio", que chamamos de hospital, deva ser pautada em ações que promovam a dignidade humana. É preciso empoderar (Vasconcelos, 2003) o paciente, escutar sua voz, garantir seus direitos de pessoa hospitalizada, reaver seu estatuto de pessoa e de sujeito (Deslandes, 2004). Finalmente, valorizar a resistência popular como um protesto legítimo contra o poder hegemônico instituído. Essas são matériasprimas políticas imprescindíveis para a construção do hospital humano.

\section{Considerações Finais}

O hospital público no Nordeste brasileiro, aqui estudado, configura-se como uma instituição total que reproduz a prisão, com suas normas restritivas e regras rigorosas. O estigma é enraizado na violência estrutural e introjetada pelo paciente, mortificando-o. A transformação do paradigma vigente em outro, humanístico e inclusivo, revela-se desafiador, pela árdua tarefa de erradicar determinantes sociais, de tão ampla magnitude, e minimizar seus efeitos na vida dos sujeitos pacientes.

Diante da complexidade do contexto de desigualdade socioeconômica e da cultura hospitalar autoritária, até que ponto o processo de humanização poderá avançar? Em virtude da imposição e da violação dos direitos do paciente, será ele impotente para exigir um atendimento digno?

Transformar o ambiente hospitalar num espaço favorável ao bem-estar das pessoas exige muito além de uma reforma física (nova decoração, áreas de lazer, cores variadas nas paredes). É necessária uma mudança de estrutura profunda da instituição: atuando nos determinantes sociais que produzem as iniqüidades em saúde, nas relações internas de poder e saber e no modelo gerencial opressivo e discriminatório; estabelecendo uma prática profissional crítica e reflexiva do agir cotidiano, pautada na democracia e numa ética humana do cuidado que dignifica o ser humano. Faz-se necessário um ensino em saúde que contemple uma visão social e humanística, integrando conteúdos das ciências sociais e humanas. O profissional, também afetado pela violência hospitalar, necessita compreender o sentido do seu trabalho, conhecer a operacionalidade do sistema público de saúde e nutrir uma generosidade que não desqualifique aquele de quem ele cuida. 
Finalmente, é preciso re-politizar o paciente, garantindo seus direitos e sua livre expressão. As reivindicações e atos de resistência contra o atendimento que agride, rotula e estigmatiza, tanto explicitamente quanto de maneira encoberta, precisam ser consideradas como um protesto legítimo contra a violência institucional; não se trata de mera reclamação, ou de queixa sem mérito. As "insatisfações do paciente" podem, na realidade, fornecer pistas valiosas para fazer acontecer o "hospital humano" no Nordeste brasileiro.

\section{Referências}

ABADIA-BARRERO, C. E.; CASTRO, A. Experiences of stigma and access to HAART in children and adolescents living with HIV/AIDS in Brazil. Social Science \& Medicine, Amsterdam, v. 62, p. 1219-1228, 2006.

BARDIN, L. Análise de conteúdo. Lisboa: Ed. 70, 2002.

BENEVIDES, R.; PASSOS, E. A humanização como dimensão política das políticas de saúde. Ciência e Saúde Coletiva, Rio de Janeiro, v. 1o. n. 3. p. 561-571, jul./set. 2005.

BERNAL, C. Cidade extrapola seus limites. Disponível em: <http://adm.noolhar.com/servlet/ opovo?event=ctdi_noticia $>$. Acesso em: 10 out. 2006.

BIBEAU, G. A step towards thick thinking: from webs of significance to connections across dimensions. Medical Anthropology Quarterly, Detroit, v. 2, p. 402-415, 1988.

BIBEAU, G.; CORIN, E. E. From submission to the text to interpretive violence. In: BIBEAU, G.; CORIN, E. E. (Ed.). Beyond textuality: asceticism and violence in anthropological interpretation. Berlin: Montonde Gruyter, 1995. p. 3-54.

BOURDIEU, P. Language and symbolic power. Cambridge: Harvard University Press, 1991.

BRASIL. Conselho Nacional de Saúde. Resolução 196/ 96. Brasília, DF, 2001.

BRASIL. Ministério da Saúde. Carta dos usuários da saúde. Brasília, DF, 2oo6a.
BRASIL. Ministério da Saúde. Secretaria Executiva. Núcleo Técnico da Política Nacional de Humanização. HumanizaSUS: política nacional de humanização: documento base para gestores e trabalhadores do SUS. Brasília, DF, 20o6b.

BRASIL. Ministério Público Federal. Assassinato de mulheres: números crescem no Cariri. Brasília, DF, 2006c. Disponível em: <www.empauta.com $>$. Acesso em: 17 maio 2006.

BUSS, P. M. Uma introdução ao conceito de promoção da saúde. In: CZERESNIA, D.; FREITAS, C. M.

Promoção da saúde: conceitos, reflexões, tendências. Rio de Janeiro: Fiocruz, 2003. p. 15-38.

CAPRA, F. O ponto de mutação. São Paulo: Círculo do Livro, 1996.

CASTRO, A.; FARMER, P. Understanding and addressing AIDS-related stigma: from anthropological theory to clinical practice in Haiti. American Journal of Public Health, Stanford, v. 59, n.1, p. 53-59, 2005 .

CHAUÍ, M. Marilena Chauí diz que Brasil convive com violência estrutural e ataca a 'oligarquia'. Disponível em <http://www.direitos.org.br/index2. php?option=com_content\&do_pdf=1\&id=1749\%20-> Acesso em: 10 out. 2006.

DESLANDES, S. F. Análise do discurso oficial sobre a humanização da assistência hospitalar. Ciência \& Saúde Coletiva, Rio de Janeiro, v. 9, n. 1, p. 7-14, jan. 2004.

DESLANDES, S. F. O projeto ético-político da humanização: conceitos, métodos e identidade. Revista Interface: comunicação, saúde, educação, Botucatu, v. 9. n. 17. p. 401-403, mar./ago. 2005.

FARMER, P. Infections and inequalities: the modern plagues. Berkeley: California Press, 1999.

FARMER, P.; CONNORS, M.; SIMMONS, J. (Ed.). Women, poverty and AIDS: sex, drugs, and structural violence. Monroe: Common Courage, 1996.

FERREIRA, A. B. H. Novo dicionário da língua portuguesa. Rio de Janeiro: Nova Fronteira, 1975. 
FOUCAULT, M. Microfísica do poder: organização, introdução e revisão técnica de Roberto Machado. 11. ed. Rio de Janeiro: Graal, 1993.

FOUCAULT, M. O nascimento da clínica. Rio de janeiro: Forense. Universitária, 1980.

GEERTZ, C. A interpretação das culturas. Rio de Janeiro: Koogan, 1989.

GIGLIO-JACQUEMOT, A. Urgências e emergências em saúde: perspectivas de profissionais e usuários. Rio de Janeiro: Fiocruz, 2005.

GOFFMAN, E. Manicômios, prisões e conventos. São Paulo: Perspectiva, 1974.

GOFFMAN, E. Stigma: notes on the management of spoiled identity. Englewood Cliffs: Prentice-Hall, 1963.

HELMAN, C. G. Cultura, saúde e doença. 4. ed. Porto Alegre: Artmed, 2003.

KLEINMAN, A. The illness narratives: suffering, healing \& the human condition. New York: Basic Books, 1988.

KLEINMAN, A. What really matters: living a moral life amidst uncertainty and danger. Oxford: Oxford University Press, 2006.

LIMA, J. C.; FAVERET, A . C.; GRABOIS, V. Planejamento participativo em organizações de saúde: o caso do Hospital Geral de Bonsucesso, Rio de Janeiro, Brasil. Cadernos de Saúde Pública, Rio de Janeiro, v. 22, n. 3, p. 631-641, mar. 2006.

LUZ, M. T. As instituições médicas no Brasil: instituições e estratégias de hegemonia. Rio de Janeiro: Graal, 1979.

LUZ, M. T. Natural, racional, social: razão médica e racionalidade científica moderna. São Paulo:

Hucitec, 2004.

LUZ, M. T. Novos saberes e práticas em saúde coletiva: estudo sobre racionalidades médicas e atividades corporais. 2. ed. São Paulo: Hucitec, 2005.
LUZ, M. T. Relações entre o adolescente e a sociedade atual: instituição, violência e disciplina. Estudos em Saúde Coletiva, Rio de Janeiro, n. 48, p. 1-17, jul. 1993. MARTINS, P. H. Contra a desumanização da medicina: crítica sociológica das práticas médicas modernas. Petrópolis: Vozes, 2003.

MORIN, E. A inteligência da complexidade. São Paulo: Petrópolis, 2000.

NATIONS, M. K.; GOMES, A. M. A. Cuidado, 'cavalo batizado' e crítica da conduta profissional pelo paciente-cidadão hospitalizado no nordeste brasileiro. Cadernos de Saúde Pública, Rio de Janeiro, v. 9, n. 23, p. 2103-2112, set. 2007.

NATIONS, M. K.; MONTE, C. M. G. I'm not dog, no!: cries of resistance against cholera control campaigns. Social Science \& Medicine, Amsterdam, v. 43, n. 6, p. 1007--1024, 1996.

NATIONS, M. K.; NUTO, S. A. S. Tooth worms, poverty tattoos and dental care conflicts in Northeast Brazil. Social Science \& Medicine, Amsterdam, v. 54, p. 229$244,2002$.

SCOTT, J. C. Domination and the arts of resistance: hidden transcripts. New Haven: Yale University Press, 1990.

SPRADLEY, J. P. The ethnographic interview. New York: Holt, Rinehart and Winston, 1979.

SWARTZ, D. Culture \& power: the sociology of Pierre Bourdieu. Chicago: University of Chicago Press, 1997.

TURNER, V. The ritual process: structure and antistructure. New York: Cornell University Press, 1969.

UCHÔA, E.; VIDAL, J. M. Antropologia médica: elementos conceituais e metodológicos para uma abordagem da saúde e da doença. Cadernos de Saúde Pública, Rio de Janeiro, v. 10, n. 4, p. 497-504, out./ dez. 1994.

VASCONCELOS, E. M. O poder que brota da dor e da opressão: empowerment, sua história, teorias e estratégias. São Paulo: Paulus, 2003. 